\title{
Subclinical Iron Overload Hampers the Beneficial Effect of Human Pegivirus (HPgV) On Disease Progression in Human Immunodeficiency Virus Type-1 Infected Blood Donors
}

\author{
Debasish Chattopadhya ${ }^{1^{*}}$, Alice Verghese ${ }^{2}$, Uma Sharma $^{3}$ and Arvind Rai ${ }^{4}$ \\ ${ }^{1}$ Additional Director, Centre for AIDS and Related Diseases, National Centre for Disease Control, Delhi, India \\ ${ }^{2}$ Assistant Research Officer, Centre for AIDS and Related diseases, National Centre for Disease Control, India \\ ${ }^{3}$ Technician, Biotechnology Division, National Centre for Disease Control, Delhi, India \\ ${ }^{4}$ Ex-Joint Director \& Head, Biotechnology Division, National Centre for Disease Control, Delhi, India
}

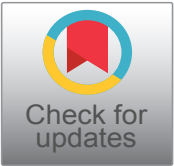

*Corresponding author: Dr. Debasish Chattopadhya, Professor, Department of Microbiology, Faculty of Medicine and Health Sciences, SGT University, Gurgaon, PIN-122505, India

\section{Abstract}

Background: Despite frequent association of Human Pegivirus (HPgV) and Torque Teno Virus (TTV) infections with Human Immunodeficiency Virus type-1 (HIV-1) infection, their roles on HIV-1 disease progression remain unclear.

Methods: A prospective study on HIV-1 disease progression was undertaken in three HIV-1 infected blood donor subgroups at early asymptomatic stages: Those with $\mathrm{HPgV}$ co-infections ( $n=60)$, with TTV co-infections $(n=48)$ and without the two co-infections $(n=54)$. Within each subgroup, both replacement and voluntary donors are examined. The markers of HIV-1 disease progression included the following virological and immunological parameters: Rate of increase in plasma HIV-1 viral load, rate of fall in CD4+ T lymphocyte count, serum levels of Tumor necrosis factor alpha (TNF- $\alpha$ ), TNF- $\alpha$ receptors (TNFRI and TNFRII), and levels of Nuclear Factor kappa beta (NF-kB) in peripheral blood mononuclear cells (PBMCs).

Results: In all the three HIV-1 infected subgroups, replacement donors displaying biochemical evidence of iron overload had higher levels of disease progression markers at enrollment and lower symptom-free survival duration on follow up compared to voluntary donors in the same subgroup. Voluntary donors in the HPgV co-infected subgroup showed significantly slower rate of HIV-1 disease progression compared to voluntary donors in the other two subgroups. Replacement donors in the HPgV co-infected subgroup that showed loss HPgV viraemia at 3 years post-enrollment were associated with faster disease progression compared to those showing persistence of HPgV viraemia at the same point.
\end{abstract}

Conclusion: The present study favors the concept that HPgV co-infection slows down disease progression in HIV1 infected individuals. However, this beneficial effect may be obliterated due to subclinical iron overload, resulting in loss of HPgV viremia consequent to fall in peripheral CD4+ T lymphocyte count.

\section{Keywords}

HIV-1, HPgV, TTV, Iron overload, Disease progression

\section{Introduction}

Human Pegivirus (HPgV) (formerly termed GBV-C/ Hepatitis $\mathrm{G}$ virus or GBV-C/HGV) and Torque Teno virus (TTV) co-infections have been frequently reported in blood donors with Human Immunodeficiency type -1 infection due to their parenteral mode of transmission [1-4]. However, studies on the effects of HPgV and TTV co-infections on HIV-1 related disease progression have yielded conflicting results [5-8]. A few reports from India on HPgV and TTV co-infections in HIV-1 infected blood donors examined their prevalence, but reports on the effect of these two co-infections on HIV-1 related disease progression in blood donors in India are limited $[9,10]$.

Our previous studies had documented biochemical evidence of iron overload in many HIV-1 seropositive blood donors due to intake of excess oral iron in an at-

Citation: Chattopadhya D, Verghese A, Sharma U, Rai A (2021) Subclinical Iron Overload Hampers the Beneficial Effect of Human Pegivirus (HPgV) On Disease Progression in Human Immunodeficiency Virus Type-1 Infected Blood Donors. Int J Virol AIDS 8:074. doi.org/10.23937/2469-567X/1510074 Accepted: March 29, 2021: Published: March 31, 2021

Copyright: (C) 2021 Chattopadhya D, et al. This is an open-access article distributed under the terms of the Creative Commons Attribution License, which permits unrestricted use, distribution, and reproduction in any medium, provided the original author and source are credited. 
tempt to maintain hemoglobin level for donating blood with high frequency. These blood donors with iron overload were characterized by heightened immune activation as reflected by the following parameters: Elevated levels of Tumor Necrosis Factor alpha (TNF- $\alpha$ ) in serum and $65 \mathrm{kDa}$ domain of nuclear factor kappa B (NF-kB p65) in nuclei of peripheral blood mononuclear cells (PBMCs), rapid fall in CD4+ T lymphocyte count, marked increase in HIV-1 viral load during asymptomatic stage followed by rapid HIV-1 disease progression and development of high incidence of pulmonary tuberculosis (PT) $[11,12]$.

The present prospective study was taken up in a group of asymptomatic HIV-1 infected blood donors co-infected with HPgV or TTV independent of other transfusion transmitted viral infections viz. Hepatitis $B$ virus (HBV) and Hepatitis C virus (HCV) in relation to serum iron parameters to find out if any alteration in such parameters could influence the effect of HPgV or TTV co-infections on the HIV-1 related disease progression.

\section{Materials and Methods}

The institutional review board and an independent institutional ethics committee approved the research proposal (NCDC/PRC/2009). Between March 2009 and February 2011, various blood banks in the National Capital Territory of Delhi and North India were requested to refer the HIV-1 seropositive blood donors (subsequently referred as donors in the paper) to the AIDS Reference Laboratory, National Center for Disease Control (NCDC), Delhi. The referring blood banks were requested to provide information about the category of the HIV-1 positive donors assigned by them as per national guideline i.e., (i)'Voluntary' donor, defined as an unpaid blood donor donating blood voluntarily in a blood bank or in a blood donation camp or (ii) 'Family/replacement' donor (commonly referred to as replacement donor), defined as a family member or a friend of the patient donating blood voluntarily for the treatment of a particular patient without any monetary or other incentive [13]. Prior to enrollment in the study, the referred donors reporting to NCDC, all males between $20-36$ years, were provided a patient information sheet and informed consent was obtained.

\section{Initial laboratory investigations}

Initially, as a part of the routine procedure followed in the NCDC AIDS Reference Laboratory, about $4 \mathrm{ml}$ of blood was collected from each of the referred donors. To confirm HIV-1 infection, $1 \mathrm{ml}$ was collected in a plain sterile tube to yield serum for confirmatory serological testing for HIV-1 infection by Western blot. The remaining $3 \mathrm{ml}$ were distributed in an ethylene-diamine-tetra-acetic acid (EDTA) vial for peripheral CD4+ T lymphocyte count (referred subsequently as CD4+ T cell count). Enumeration of peripheral CD4+ T cell count was done by FACS Count Method using labeled monoclonal CD4/
CD3 reagent and analysis by FACS Count Machine (FACS Count Model No. D0433, SW Version1.0 08/05, BD Biosciences, San Jose, CA 95131) [14].

\section{Clinical staging of the HIV-1 positive donors}

All the donors confirmed to be seropositive for HIV1 infection were referred to clinical specialists at designated referral centers for clinical staging as per national guidelines based on WHO criteria for clinical staging $[15,16]$. Only HIV-1 positive donors diagnosed to be at the asymptomatic stage for HIV-1 infection by clinicians and unimpaired CD4+ T cell count (more than $500 / \mu \mathrm{L}$ in triplicate measurements) were included in the present study for further epidemiological and laboratory investigations. Few donors $(n=3)$ presenting as asymptomatic but with CD4+ T cell counts 400-500/ $\mu$ l were omitted.

\section{Collection of epidemiological information}

A confidential interview was conducted with HIV-1 positive donors to collect information on HIV related risk behaviors (e.g. unprotected sex with high risk heterosexual and/or homosexual partner, parenteral drug abuse, or receipt of blood transfusion). Considering that many of the HIV-1 positive donors admitted single unprotected sexual exposure to female commercial sex workers (CSWs) as their only HIV-1 related risk behavior. They were further inquired about the time of exposure to estimate the duration of infection. However, HIV-1 positive donors with a history of recurrent high-risk exposures to female CSWs, the probable duration of infection could not be ascertained. Additionally, donors were asked to provide their history regarding regular non-dietary intake whereby many donors in the replacement category reported iron as their only regular non-dietary supplement. The donors with a positive history of iron supplementation were asked to provide their rationale although detailed information regarding quantity and duration of iron supplementation were not recorded due to a lack of definite recall.

\section{Additional laboratory investigation}

The enrolled HIV-1 positive donors were subjected to further biochemical, serological, molecular, immunological and virological investigations.

Collection of blood samples: About $20 \mathrm{ml}$ of blood was collected from each subject, $5 \mathrm{ml}$ in plain sterile tube to yield serum and $15 \mathrm{ml}$ in an EDTA container. Part of the serum was utilized for measurement of (i) Iron, transferrin saturation (\%), and ferritin level as indicators of body iron status (ii) Albumin, bilirubin, and liver enzymes as indicators of liver function and (iii) TNF- $\alpha$, TNFRI, and TNFRII levels as markers of immune activation status. Remaining serum was used for (i) Serological detection of Syphilis, serological/molecular detection of Hepatitis B virus (HBV), and Hepatitis C virus (HCV) infections and (ii) Molecular detection of HPgV and TTV infections. Blood collected in EDTA was utilized for plas- 
ma viral load assay and quantitation of NF-kB p65 in nuclei of PBMCs, both as indicators of disease progression.

Measurement of iron parameters, bilirubin and liver enzymes levels in serum: Measurements of serum ferritin, iron, and transferrin saturation (\%) levels were carried out as previously described [11]. Measurements of serum albumin, bilirubin, and liver enzymes viz. alanine aminotransferase (ALT), aspartate aminotransferase (AST), alkaline phosphatase (ALP) were carried out using auto-analyzer (Hitachi 912, Hitachi Ltd., Japan) [17]. Cut off upper limit of normal values for serum bilirubin, ALT, AST and ALP were considered as $1.2 \mathrm{mg} / \mathrm{dL}$, $55 \mathrm{U} / \mathrm{L}, 48 \mathrm{U} / \mathrm{L}$ and $129 \mathrm{U} / \mathrm{L}$ respectively [18].

Serological Screening for Syphilis, HBV and HCV infections: Part of the serum collected from the donors confirmed as seropositive for HIV-1 infection was utilized for laboratory investigations to exclude donors with serological/molecular evidence of Syphilis, HBV, and HCV infections as follows.

Serological screening tests were carried out for Syphilis by the Treponema pallidum hemagglutination (TPHA) test (Fujirebio, Tokyo, Japan). For HBV infection, an Enzyme Linked Immunosorbent Assay (ELISA) was employed using three markers: hepatitis $B$ surface antigen ( $\mathrm{HBsAg})$, antibody to Hepatitis B surface antigen (anti-HBs) and antibody to Hepatitis B core antigen (anti- $\mathrm{HBc}$ ) while screening for $\mathrm{HCV}$ infection was also evaluated via ELISA as previously described [11]. All the ELISA kits for HBV and HCV infections were commercially procured (Abbott laboratories, North Chicago, IL, USA) and tests were performed as per manufacturer's protocols.

Molecular detection of HBV, TTV, HPgV and HCV: Molecular detection of HBV, TTV, HPgV and HCV were carried out by polymerase chain reaction (PCR) using pre-published primer sequences, extraction techniques, thermal cycling conditions and detection of specific bands as described earlier [19] (Supplementary material 1).

In order to avoid confounding effects of other common transfusion mediated infections, only the asymptomatic HIV-1 infected donors negative for Syphilis (by serology), HBV and HCV infections (by both serological and molecular methods) with HPgV or TTV co-infections were included in the present study.

Plasma viral load assay: This was carried out employing commercial viral load assay kit (Amplicor HIV Monitor assay, version 1.5, Roche Molecular systems, Branchburg, NJ, USA) with sensitivity of 200 copies per $\mathrm{ml}[20]$.

Quantitation of NF-kB p65 level in nuclei of LPS stimulated PBMCs: NF-kB in nuclear extracts of Lipopolysaccharide (LPS) stimulated PBMCs were quantified by following a modified protocol from Zheng, et al. [21] as described previously $[11,22]$. Broadly, the protocol consists of four steps: (i) Isolation of PBMCs (ii) Treat- ment of PBMCs with LPS to induce translocation of NFkB p65 from cytoplasm into the nucleus (iii) Extraction of nuclear proteins from LPS stimulated PBMCs and (iv) Estimation of NF-kB p65 in nuclear protein extracts of LPS stimulated PBMCs (Supplementary material 2).

\section{Clinical and Laboratory Follow Up}

\section{Clinical follow up}

All donors in this study that were registered with clinicians were also advised to enroll in anti-retroviral therapy (ART) centers and report any illness to the clinician (AIDS-related or not) during the follow up period. The time for development of any AIDS related illness (ARI) diagnosed by the clinician based on national guidelines and WHO criteria $[15,16]$ was recorded to estimate duration of HIV-1 symptom-free survival. In the case of a donor reporting multiple ARI-related symptoms, the onset of the first such symptom was considered as the time of ARI development to calculate disease free survival duration. None of the HIV-1 positive donors in the present study opted to enroll in an ART program prior to development of ARI. Additionally, no donor was put on any chemoprophylaxis during the asymptomatic phase.

\section{Laboratory follow up}

\section{Virological follow up:}

(i) HIV-1 viral load: Considering plasma virus levels at early stage of HIV-1 infection are well-known to be unstable until 6-12 months post-infection following which they are relatively stable (i.e., viral set point), changes in HIV-1 viral load were assessed between the $1^{\text {st }}$ and $2^{\text {nd }}$ year of post-enrollment follow up (detailed further in the results section) $[11,23]$.

(ii) Detection of HPgV and TTV viraemia: Loss or persistence of HPgV and TTV viraemia on follow up in HIV1/HPgV and HIV-1/TTV subgroups were based on molecular detection of these two agents (detailed above) after three years post-enrollment.

\section{Follow up of biochemical parameters:}

(i) Serum iron parameters: Serum levels of iron, transferrin saturation (\%) and ferritin were repeated after one year post-enrollment to record any change consequent to discontinuation of consumption of iron tablets reported by the donors following diagnosis of HIV-1 infection.

(ii) Liver function parameters: Laboratory investigations related to liver function were repeated at the same time as HPgV and TTV detection ( 3 years post-enrollment) to assess effects of HPgV and TTV co-infections on liver function.

Follow up of immunological parameters: Peripheral CD4+ T cell count, serum levels of TNF- $\alpha$, TNFRI, TNFRII, and levels of NF-kB p65 in nuclear extracts of LPS stimulated PBMCs were repeated one year post-enrollment to record the trend of changes during the period. 


\section{Non-Donor Community Controls}

Fifty blood samples from randomized age, sex and socioeconomically matched healthy individuals within the local community without any reported history of HIV-1-related risk behavior and screened as negatives for HIV-1, HBV, HCV, Syphilis, HPgV and TTV were enrolled in the study as non-donor community controls. The community controls were subjected to all additional laboratory investigations carried out for HIV-1 positive donors at enrollment (except HIV-1 viral load).

\section{Statistics}

Univariate analysis was undertaken for each of the various laboratory parameters. For laboratory parameters of the donors with normal distribution characteristics, chi square test for categorical variables and student's t-test or one-way ANOVA followed by post-hoc test with Bonferroni adjustment for continuous variables were utilized. Continuous variables not conforming to a normal distribution pattern were compared by Kruskal Wallis test followed by multiple comparisons using Mann Whitney test with Bonferroni adjustment.

Symptom free survival duration was calculated as the interval from the date of detection of seropositivity at the referring blood banks to the development of ARI as diagnosed by clinicians and reported as the median (months) with 95\% confidence interval (Cl). Kaplan-Meier method was employed to compare disease progression pattern in various subgroups and categories using log-rank $\chi^{2}$ test [11].

Rate of fall in CD4 $+T$ cell count was expressed as monthly average while rate of increase in plasma viral load was expressed as increase per year on the basis of their values recorded at enrollment and after one year of post-enrollment follow up. All the laboratory parameters estimated at enrollment in the replacement category of HIV-1 positive donors with HPgV co-infection were retrospectively analyzed in relation to persistence or loss of HPgV viremia recorded at $3^{\text {rd }}$ year of post-enrollment follow up. Such analysis could not be undertaken in the voluntary category of donors in the same subgroup since there was only one donor that showed loss of HPgV viremia at follow up point. P value $<0.05$ was considered as statistically significant, and it was adjusted for multiple comparisons. Fisher's exact test was used if any of the cell values were less than five.

\section{Results}

\section{Distribution and characteristics of HIV-1 positive donors based on co-infection}

A total of 162 HIV-1 positive donors were enrolled in the present study on the basis of being clinically asymptomatic and screened to be negative for HBV/HCV/ Syphilis infection at our center. These comprised of 60 (37.1\%), 48 (29.6\%) and 54 (33.3\%) of HIV-1 infected donors co-infected with HPgV (HIV-1/HPgV, subgroup
I), with TTV (HIV-1/TTV, subgroup II) and without HPgV or TTV co-infection (subgroup III), respectively. Replacement donors consisted of 38 (63.3\%) donors in subgroup I, 16 (33.3\%) donors in subgroup II, and 19 (35.2\%) donors in subgroup III, while the remaining donors in each of the three subgroups were voluntary donors. Positive history of regular intake of oral iron tablets was disclosed by $20(52.6 \%), 8(50 \%)$ and $9(47.4 \%)$ of replacement donors in subgroups I, II and III, respectively, admitting such history to be as a precautionary measure to maintain hemoglobin level (donation eligibility), despite not having any documented clinical or laboratory evidence of iron deficiency. Notably, none of the HIV-1 positive donors in voluntary category in any subgroup gave history of such iron intake.

Only 93 (57.4\%) donors disclosed history of single unprotected sexual exposure with female CSW between 2-8 months prior to HIV-1 positive blood donation. These cases comprised $42(70 \%)$ in subgroup I, 29 $(60.4 \%)$ in subgroup II and $22(40.7 \%)$ in subgroup III. An additional 2 donors in the replacement category of subgroup I disclosed multiple exposures during the preceding 2 years. None of the donors had any record of prior HIV test result available with them and none had history of other HIV-1 related risk behavior (e.g., parenteral drug abuse or receipt of blood/ blood product).

\section{Follow up molecular testing of HPgV in HIV-1/ HPgV infected donors}

Follow up molecular testing of HPgV in the HIV-I/ $\mathrm{HPgV}$ subgroup at 3 years post-enrollment demonstrated detectable HPgV loss in 36 out of 56 (64.3\%) donors in the replacement category and in only 1 out of $20(5 \%)$ in the voluntary category (relative risk 8.5). On the other hand, there was no loss of TTV in HIV-1/TTV subgroup at the same point of follow up.

\section{Serum levels of iron, transferrin saturation (\%), ferritin and liver enzymes}

Serum levels of iron, transferrin saturation index, and ferritin at enrollment were elevated in the replacement category of HIV-1 positive donors and unaltered in voluntary donors in all the subgroups compared to non-donor community controls. Further, retrospective analysis showed that among the replacement donors in HIV-1/HPgV subgroup, those demonstrating loss of $\mathrm{HPgV}$ viremia on follow up had significantly higher levels of iron parameters at enrollment compared to those demonstrating persistence of HPgV viremia (Table 1). There were many HIV-1 positive donors with or without HPgV co-infection who did not admit any history of oral iron intake but showed elevated levels of serum iron parameters in blood (> Mean +2 SD of non-donor controls, data not shown). Elevated levels of all the iron parameters in replacement donors came down to normal levels in all the three subgroups at the one year post-enrollment follow up point (Supplementary material 3). 
Table 1: Levels of iron parameters in various co-infected subgroups of HIV-1 positive donors at enrollment.

\begin{tabular}{|c|c|c|c|c|c|c|c|c|c|}
\hline & & \multicolumn{8}{|c|}{ Subgroups of various co-infections in HIV-1 +ve donors } \\
\hline & & \multicolumn{4}{|c|}{$\begin{array}{l}\mathrm{HPgV}+\mathrm{ve} \\
(\mathrm{n}=60)\end{array}$} & \multicolumn{2}{|c|}{$\begin{array}{l}\text { TTV +ve } \\
(\mathrm{n}=48)\end{array}$} & \multicolumn{2}{|c|}{$\begin{array}{c}\text { HPgV -ve/TTV -ve } \\
(n=54)\end{array}$} \\
\hline \multirow{3}{*}{\multicolumn{2}{|c|}{ Levels of iron parameters }} & \multicolumn{3}{|c|}{$\begin{array}{c}\text { Rep } \\
(n=38)\end{array}$} & \multirow[t]{3}{*}{$\begin{array}{c}\text { Vol } \\
(n=22)\end{array}$} & \multirow[t]{3}{*}{$\begin{array}{c}\text { Rep } \\
(n=16)\end{array}$} & \multirow[t]{3}{*}{$\begin{array}{c}\text { Vol } \\
(n=32)\end{array}$} & \multirow[t]{3}{*}{$\begin{array}{c}\text { Rep } \\
(n=19)\end{array}$} & \multirow[t]{3}{*}{$\begin{array}{c}\text { Vol } \\
(n=35)\end{array}$} \\
\hline & & \multicolumn{3}{|c|}{$\mathrm{HPgV}$ viremia on follow up } & & & & & \\
\hline & & $\begin{array}{c}\text { Total } \\
(n=38)\end{array}$ & $\begin{array}{c}\text { Neg } \\
(n=24)\end{array}$ & $\begin{array}{c}\text { Pos } \\
(n=14)\end{array}$ & & & & & \\
\hline Serum iron & Mean & 31.9 & 41.9 & 26.1 & 14.9 & 31.3 & 14.1 & 28.1 & 13.1 \\
\hline$(\mu \mathrm{mol} / \mathrm{L})$ & $\mathrm{SD}$ & $10.6^{*}$ & $3.9^{* *}$ & 8.7 & 4.4 & $4.9^{*}$ & 4.1 & $6.2^{*}$ & 2.6 \\
\hline \multirow{2}{*}{$\begin{array}{c}\text { Transferrin } \\
\text { saturation (\%) }\end{array}$} & Mean & 52.4 & 62.8 & 46.2 & 33.2 & 48.4 & 34.3 & 53.6 & 32.8 \\
\hline & SD & $10.3^{*}$ & $5.6^{* *}$ & 6.3 & 4.9 & $9.6^{*}$ & 4.2 & $7.5^{*}$ & 6.6 \\
\hline \multirow{2}{*}{$\begin{array}{l}\text { Serum ferritin } \\
\qquad(\mu \mathrm{g} / \mathrm{L})\end{array}$} & Mean & 225 & 299 & 171 & 74 & 208 & 72 & 211 & 75 \\
\hline & SD & $76.4^{*}$ & $41.5^{* *}$ & 46.5 & 9.5 & $31.2^{*}$ & 8.8 & $33^{*}$ & 8.9 \\
\hline
\end{tabular}

Statistical Comparisons: ${ }^{*} \mathrm{P}<0.001$ vs. Voluntary $(\mathrm{Vol}),{ }^{* *}$ Significantly higher value vs. Pos $(p<0.001)$.

Note: The mean \pm SD levels in non-donor controls $(n=50)$ for serum iron ( $\mu \mathrm{mol} / \mathrm{L})$, transferrin saturation $(\%)$ and serum ferritin $(\mu \mathrm{g} / \mathrm{L})$ were $16.6 \pm 3.2,31.4 \pm 4.6$ and $80 \pm 26.8$ respectively.

Serum levels of liver enzymes and bilirubin in all the subgroups at enrollment were comparable to non-donor controls regardless of their categories i.e. replacement or voluntary. Follow up assessment of serum levels of albumin, liver enzymes and bilirubin at $3^{\text {rd }}$ year post-enrollment showed no statistically significant change compared to their enrollment levels (Supplementary material 3).

\section{CD4 + T cell counts and HIV-1 plasma viral load at enrollment and at follow up point}

All HIV-1 infected donors in the present study had comparable $\mathrm{CD} 4+\mathrm{T}$ cell counts between the three subgroups at enrollment as well as rate of fall in CD4+ $T$ cell count recorded over one year of post-enrollment period. However, further analysis of these parameters in relation to category of donors revealed that the rate in decline in CD4+ T cell count was significantly higher in replacement donors compared to voluntary donors in all the three subgroups. Retrospective analysis of CD4+ $T$ cell count in relation to persistence or loss of HPgV viremia in HIV-1/HPgV replacement donors revealed that the donors demonstrating loss of HPgV viraemia had significantly higher rate of fall in $\mathrm{CD} 4+\mathrm{T}$ cell count at enrollment compared to those demonstrating persistence of HPgV viraemia at the same point. However, the rate of CD4+ $T$ cell count decline was significantly lower among HIV-1/HPgV voluntary donors as compared to the similar category of donors in other subgroups. Notably, the lower rate of decline in HIV-1/HPgV voluntary donors was masked when assessing the whole HIV-1/ $\mathrm{HPgV}$ subgroup due to high rate of CD4 cell decline seen in replacement donors within the same subgroup (Table 2).
The HIV-1 positive donors showed wide variation in plasma viral load at enrollment ( $\log _{10}$ copies / $\mathrm{ml}$ ranging between 3 and 6) with substantial deviation from normal distribution pattern. However, plasma viral load assumed a normal distribution pattern with much less variation at first year post-enrollment (considered as viral set point or baseline value in the present study). Rate of increase in plasma viral load between first and second year of post-enrollment was significantly higher among replacement donors compared to voluntary donors in all the subgroups. Rate of increase in plasma viral load was significantly lower in HIV-1/HPgV voluntary donors in comparison to voluntary donors in other subgroups. However, similar to what was observed with the rate of fall in CD4 cell count, the slower rate of increase in plasma viral load in voluntary donors in the HIV-1/HPgV subgroup was masked when was assessed in terms of the whole subgroup due to opposing effect i.e. faster rate of increase in replacement donors within the same subgroup. Retrospective analysis of the viral load among HIV-1/HPgV replacement donors revealed that those demonstrating loss of $\mathrm{HPgV}$ viremia on follow up were characterized by significantly higher degree of rise in plasma viral load between first year and second year of post-enrollment assessment compared to those demonstrating persistence of $\mathrm{HPgV}$ viremia at the same time point (Table 2).

\section{Levels of immune activation markers in serum and NF-kB in nuclear extracts of PBMC}

Serum levels of the three immune activation markers studied i.e. TNF- $\alpha$, TNFRI and TNFRII, were found to be significantly higher among replacement donors compared to voluntary donors at enrollment for all sub- 
Table 2: CD4+ T cell count and HIV-1 viral load at enrollment and rates of their changes during follow up in various co-infected subgroups of HIV-1 positive donors.

\begin{tabular}{|c|c|c|c|c|c|c|c|c|c|c|}
\hline & & & \multicolumn{8}{|c|}{ Subgroups of various co-infections in HIV-1 +ve donors } \\
\hline & & & \multicolumn{4}{|c|}{$\begin{array}{l}\mathrm{HPgV}+\mathrm{ve} \\
(\mathrm{n}=60)\end{array}$} & \multicolumn{2}{|c|}{$\begin{array}{l}\text { TTV +ve } \\
(n=48)\end{array}$} & \multicolumn{2}{|c|}{$\begin{array}{c}\mathrm{HPgV}-\mathrm{ve} / \mathrm{TTV}-\mathrm{ve} \\
(\mathrm{n}=54)\end{array}$} \\
\hline & & & & $\begin{array}{c}\text { Rep } \\
(n=38)\end{array}$ & & $\begin{array}{c}\text { Vol } \\
(n=22)\end{array}$ & $\begin{array}{c}\text { Rep } \\
(n=16)\end{array}$ & $\begin{array}{c}\text { Vol } \\
(n=32)\end{array}$ & $\begin{array}{c}\text { Rep } \\
(n=19)\end{array}$ & $\begin{array}{c}\text { Vol } \\
(n=35)\end{array}$ \\
\hline \multirow{2}{*}{\multicolumn{3}{|c|}{ Assessment parameters Level }} & $\mathrm{HPgV} v$ & emia on $f$ & llow up & & & & & \\
\hline & & & Total & Neg & Pos & & & & & \\
\hline \multirow{4}{*}{ CD4+ T cell } & Count/Cumm & Mean & 800 & 806 & 795 & 759 & 750 & 802 & 777 & 756 \\
\hline & & SD & 101 & 112 & 96 & 134 & 106 & 100 & 88 & 106 \\
\hline & Rate of fall ${ }^{*}$ & Mean & 7.5 & 10.4 & 5.8 & 2.2 & 6.9 & 4.5 & 7.3 & 4.8 \\
\hline & & SD & 2.6 & $1.4^{\mathrm{a}}$ & 1.1 & $0.8^{b, c}$ & 2.6 & 1.1 & 1.6 & 1.1 \\
\hline \multirow{4}{*}{ HIV-1 viral load } & Level & Mean & 4.1 & 4.1 & 4.1 & 3.4 & 3.8 & 3.7 & 3.8 & 3.6 \\
\hline & $\left(\log _{10}\right)$ & SD & 0.11 & 0.15 & 0.1 & 0.1 & 0.15 & 0.19 & 0.15 & 0.2 \\
\hline & Rate of & Mean & 0.33 & 0.49 & 0.25 & 0.12 & 0.25 & 0.2 & 0.26 & 0.24 \\
\hline & $\begin{array}{c}\text { increase } \\
\left(\log _{10}\right)^{* *}\end{array}$ & SD & 0.14 & $0.09^{a}$ & 0.08 & $0.04^{b, c}$ & 0.1 & 0.08 & 0.12 & 0.1 \\
\hline
\end{tabular}

"Indicates changes per month over I year of post-enrollment follow up; ${ }^{* *}$ Indicates changes per year between $1^{\text {st }}$ and $2^{\text {nd }}$ year of post-enrollment follow up (vide materials and methods).

Statistical comparisons: a: Significantly higher value vs. Pos $(p<0.001)$; b: Significantly lower value compared to replacement (Rep) category of donors in HPgV +ve subgroup $(\mathrm{p}<0.001)$; c: Significantly lower value in voluntary $(\mathrm{Vol})$ donors in HPgV +ve subgroup compared to similar category of donors in other two subgroups $(p<0.001)$.

Note: The mean \pm SD value for CD4+ T cell count/cumm in non-donor controls $(n=50)$ was $802 \pm 178$.

Table 3: Serum levels (pg/ml) of activation markers in various co-infected subgroups of HIV-1 positive donors.

\begin{tabular}{|c|c|c|c|c|c|c|c|c|c|c|}
\hline & & & \multicolumn{8}{|c|}{ Subgroups of various co-infections in HIV-1 +ve donors } \\
\hline \multirow{4}{*}{\multicolumn{3}{|c|}{ Activation markers }} & \multicolumn{4}{|c|}{$\begin{array}{l}\mathrm{HPgV}+\mathrm{ve} \\
(\mathrm{n}=60)\end{array}$} & \multicolumn{2}{|c|}{$\begin{array}{l}\text { TTV +ve } \\
(\mathrm{n}=48)\end{array}$} & \multicolumn{2}{|c|}{$\begin{array}{c}\mathrm{HPgV}-\mathrm{ve} / \mathrm{TTV}-\mathrm{ve} \\
(\mathrm{n}=54)\end{array}$} \\
\hline & & & \multicolumn{3}{|c|}{$\begin{array}{c}\text { Rep } \\
(n=38)\end{array}$} & \multirow[t]{3}{*}{$\begin{array}{c}\text { Vol } \\
(n=22)\end{array}$} & \multirow[t]{3}{*}{$\begin{array}{c}\text { Rep } \\
(n=16)\end{array}$} & \multirow[t]{3}{*}{$\begin{array}{c}\text { Vol } \\
(n=32)\end{array}$} & \multirow[t]{3}{*}{$\begin{array}{c}\text { Rep } \\
(n=19)\end{array}$} & \multirow[t]{3}{*}{$\begin{array}{c}\text { Vol } \\
(n=35)\end{array}$} \\
\hline & & & \multicolumn{3}{|c|}{$\mathrm{HPgV}$ viremia on follow up } & & & & & \\
\hline & & & $\begin{array}{c}\text { Total } \\
(n=38)\end{array}$ & $\begin{array}{c}\text { Neg } \\
(n=24)\end{array}$ & $\begin{array}{c}\text { Pos } \\
(n=14)\end{array}$ & & & & & \\
\hline \multirow{4}{*}{ TNFa } & \multirow[t]{2}{*}{ En } & Mean & 8.4 & 13 & 4.5 & 0.43 & 6.4 & 3.1 & 7.1 & 1.8 \\
\hline & & SD & 4.2 & $3.2^{\mathrm{a}}$ & 1.4 & $0.47^{b}$ & 2.3 & 0.8 & 1.8 & 0.8 \\
\hline & \multirow[t]{2}{*}{$\mathrm{Fu}$} & Mean & 5.8 & 9.4 & 3.7 & 0.87 & 4.6 & 5.12 & 4.8 & 6.9 \\
\hline & & SD & 3.2 & $2.3^{a}$ & 1.1 & $0.4^{\mathrm{b}}$ & 1.9 & 0.89 & 1.3 & 0.8 \\
\hline \multirow{4}{*}{ TNFRI } & \multirow[t]{2}{*}{ En } & Mean & 11.5 & 20.1 & 6.6 & 2.9 & 10.7 & 6.1 & 9.4 & 6.6 \\
\hline & & SD & 7.4 & $4.6^{a}$ & 2.1 & $1.7^{b}$ & 3.6 & 1.57 & 2.1 & 1.4 \\
\hline & \multirow[t]{2}{*}{$\mathrm{Fu}$} & Mean & 8.8 & 16.8 & 4.1 & 3.2 & 7.9 & 6.5 & 6.7 & 8.6 \\
\hline & & SD & 6.5 & $2.8^{a}$ & 1.4 & $1.5^{b}$ & 2.9 & 1.6 & 2.1 & 1.4 \\
\hline \multirow{4}{*}{ TNFRII } & \multirow[t]{2}{*}{ En } & Mean & 15.9 & 31.1 & 7.1 & 4.9 & 22.8 & 11.5 & 26.2 & 12.8 \\
\hline & & SD & 12.3 & $5.9^{\mathrm{a}}$ & 1.8 & $1.7^{b}$ & 15.2 & 3.6 & 8.7 & 4.2 \\
\hline & \multirow[t]{2}{*}{$\mathrm{Fu}$} & Mean & 10.6 & 19.9 & 5.3 & 6.0 & 14.4 & 12.9 & 15.1 & 15.8 \\
\hline & & SD & 7.5 & $3.5^{\mathrm{a}}$ & 1.2 & $1.7^{b}$ & 3.8 & 4.8 & 4.12 & 4.6 \\
\hline
\end{tabular}

Statistical comparisons: a: Significantly higher value vs. Pos $(p<0.001)$ at enrollment (En) as well as on follow up (Fu); b: Significantly lower value in voluntary (Vol) category of donors in HPgV co-infected subgroup vs. similar category of donors in other subgroups ( $p$ values $<0.001$ ) at enrollment (En) as well as on follow up (Fu)

Note: The mean \pm SD $(\mathrm{pg} / \mathrm{ml})$ values for serum levels of TNF- $\alpha$, TNFRI and TNFRII in non-donor controls $(n=50)$ were $2 \pm 0.5$, $1.5 \pm 0.3$ and $2 \pm 0.4$ respectively. 
groups. In particular, the levels of immune activation at enrollment were significantly lower among HIV-1/ $\mathrm{HPgV}$ voluntary donors compared to voluntary donors in other subgroups. Moreover, higher proportions of the voluntary donors showed undetectable levels of the activation markers in serum at enrollment in the HIV$1 / \mathrm{HPgV}$ subgroup compared to voluntary donors in the other two subgroups (data not shown in table). Levels of the three activation markers continued to remain raised with respect to replacement donors in all the subgroups as assessed at follow up point despite significant decline. Voluntary donors in all the subgroups showed marginal but statistically insignificant rise in levels of all the three activation markers upon follow up (Table 3 ).

Levels of NF-kB p65 in nuclear extracts of LPS stimulated PBMCs at enrollment followed the pattern similar to that observed for serum immune activation markers in all the three subgroups (Table 4).
Retrospective analysis comparing immune activation markers (enrollment and follow up) with loss or persistence of detectable HPgV viraemia in HIV-1/HPgV replacement donors revealed higher serum levels of TNF- $\alpha$, TNFRI, TNFRII and higher level of NF-KB in LPS stimulated PBMCs in the donors showing loss of HPgV viremia compared to those with persistent viremia (Tables 3 and Table 4).

\section{Symptom free interval}

On clinical follow up, the overall pattern of HIV-1 disease progression was similar in all three subgroups, as assessed on the basis of median symptom free survival time ( $p=$ NS on multiple comparisons). However, further analysis showed disease progression to be more rapid in replacement donors as opposed to voluntary donors in each subgroup (Table 5). In particular, disease progression was significantly slower among HIV-1/HPgV

Table 4: NF-kB levels (ng/ug of protein) in nuclear extracts of LPS stimulated PBMCs in various co-infected subgroups of HIV-1 positive donors.

\begin{tabular}{|c|c|c|c|c|c|c|c|c|c|}
\hline & & \multicolumn{8}{|c|}{ Subgroups of various co-infections in HIV-1 +ve donors } \\
\hline & & \multicolumn{4}{|c|}{$\begin{array}{l}\mathrm{HPgV}+\mathrm{ve} \\
(\mathrm{n}=60)\end{array}$} & \multicolumn{2}{|c|}{$\begin{array}{l}\text { TTV +ve } \\
(n=48)\end{array}$} & \multicolumn{2}{|c|}{$\begin{array}{c}\text { HPgV -ve/TTV -ve } \\
(n=54)\end{array}$} \\
\hline & & & $\begin{array}{c}\text { Rep } \\
(n=38)\end{array}$ & & $\begin{array}{c}\text { Vol } \\
(n=22)\end{array}$ & $\begin{array}{c}\text { Rep } \\
(n=16)\end{array}$ & $\begin{array}{c}\text { Vol } \\
(n=32)\end{array}$ & $\begin{array}{c}\text { Rep } \\
(n=19)\end{array}$ & $\begin{array}{c}\text { Vol } \\
(n=35)\end{array}$ \\
\hline & & $\mathrm{HPg}$ & emia on $f$ & ow up & & & & & \\
\hline \multicolumn{2}{|c|}{ 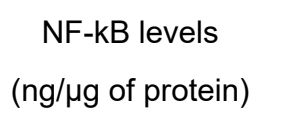 } & $\begin{array}{l}\text { Total } \\
\text { Rep }\end{array}$ & $\begin{array}{c}\text { Neg } \\
(n=24)\end{array}$ & $\begin{array}{c}\text { Pos } \\
(n=14)\end{array}$ & & & & & \\
\hline \multirow[t]{2}{*}{ En } & Mean & 12.1 & 20.4 & 6.9 & 0.3 & 10.3 & 2.4 & 9.7 & 2.1 \\
\hline & SD & 8.1 & $6.5^{\mathrm{a}}$ & 2.6 & $0.3^{b}$ & 4.2 & 1.2 & 3.1 & 0.8 \\
\hline \multirow[t]{2}{*}{$\mathrm{Fu}$} & Mean & 6.9 & 13.9 & 2.7 & 0.7 & 5.3 & 4.9 & 5.1 & 2.6 \\
\hline & SD & 6.4 & $4.9^{a}$ & 1.8 & $0.4^{\mathrm{b}}$ & 2.3 & 2.1 & 2.1 & 1.9 \\
\hline
\end{tabular}

Statistical comparisons: a: Significantly higher values, vs. Pos $(p<0.001)$ at enrollment (En) as well as on follow up (Fu); b: Significantly lower value in Vol category of donors in HPgV +ve subgroup vs. similar category of donors in other two subgroups ( $p$ $<0.001)$ at enrollment (En) as well as on follow up (Fu)

Note: The mean \pm SD level of NF-kB ( $n g / \mu g$ of protein) in non-donor controls $(n=50)$ was $0.48 \pm 0.08$.

Table 5: Symptom free survival duration (months) in various co-infected subgroups of HIV-1 positive donors.

\begin{tabular}{|c|c|c|c|c|}
\hline & & \multicolumn{3}{|c|}{ Subgroups of various co-infections in HIV-1 +ve donors } \\
\hline \multicolumn{2}{|c|}{ Category of donors } & $\begin{array}{l}\mathrm{HPgV}+\mathrm{ve} \\
(\mathrm{n}=60)\end{array}$ & $\begin{array}{l}\text { TTV +ve } \\
(n=48)\end{array}$ & $\begin{array}{c}\text { HPgV -ve/TTV -ve } \\
(n=54)\end{array}$ \\
\hline Replacement & $\begin{array}{l}\text { Median } \\
(95 \% \mathrm{Cl})\end{array}$ & $\begin{array}{c}72 \\
(68-74)\end{array}$ & $\begin{array}{c}68 \\
(66-72)\end{array}$ & $\begin{array}{c}68 \\
(64-71)\end{array}$ \\
\hline Voluntary & $\begin{array}{l}\text { Median } \\
(95 \% \mathrm{Cl})\end{array}$ & $\begin{array}{c}110^{*} \\
(101-116)\end{array}$ & $\begin{array}{c}80 \\
(76-83)\end{array}$ & $\begin{array}{c}82 \\
(79-88)\end{array}$ \\
\hline Total subgroup & $\begin{array}{l}\text { Median } \\
(95 \% \mathrm{Cl})\end{array}$ & $\begin{array}{c}88 \\
(74-101)\end{array}$ & $\begin{array}{c}78 \\
(72-80)\end{array}$ & $\begin{array}{c}76 \\
(73-81)\end{array}$ \\
\hline
\end{tabular}

Statistical Comparisons: *Significantly longer duration of symptom free survival in HIV-1/HPgV +ve subgroup compared to other subgroups ( $p<0.001$ for both comparisons).

Note: Within the replacement category of HIV-1 infected donors with HPgV co-infections, the subcategory showing loss of HPgV viremia on follow up had significantly shorter duration of symptom free survival (Median, $95 \% \mathrm{Cl}$ as $61,57-64$ ) compared to the subcategory demonstrating persistence of $\mathrm{HPgV}$ viremia (Median, $95 \% \mathrm{Cl}$ as $80,73-86 ; \mathrm{p}<0.001$ ) at the same point. 
voluntary donors over the voluntary donors in other subgroups at same point ( $p<0.001$, Figure 1$)$. Among HIV-1/HPgV replacement donors, those with loss of detectable HPgV viremia at third year of follow up point had faster disease progression compared to those with persistent HPgV viremia (Table 5 and Figure 2).

\section{Discussion}

Numerous studies from India had documented a high prevalence of HIV-1 infection as a result of paid blood donors partaking in high-risk HIV-related behav- iors, causing blood recipients to be infected with HIV1 (especially the multi- transfused groups) [24,25]. To solve this problem, a legal ban on paid blood donations was imposed in the country in 1996. However, India continues to face blood donation shortages by relying solely on the voluntary sector [13]. As a consequence, India is heavily reliant on replacement donors, constituting as high as $45 \%$ of nation's blood supply [13]. Concerns have been raised about replacement donors presenting as family members or close friends of the patient in exchange for financial or other gains $[26,27]$. In

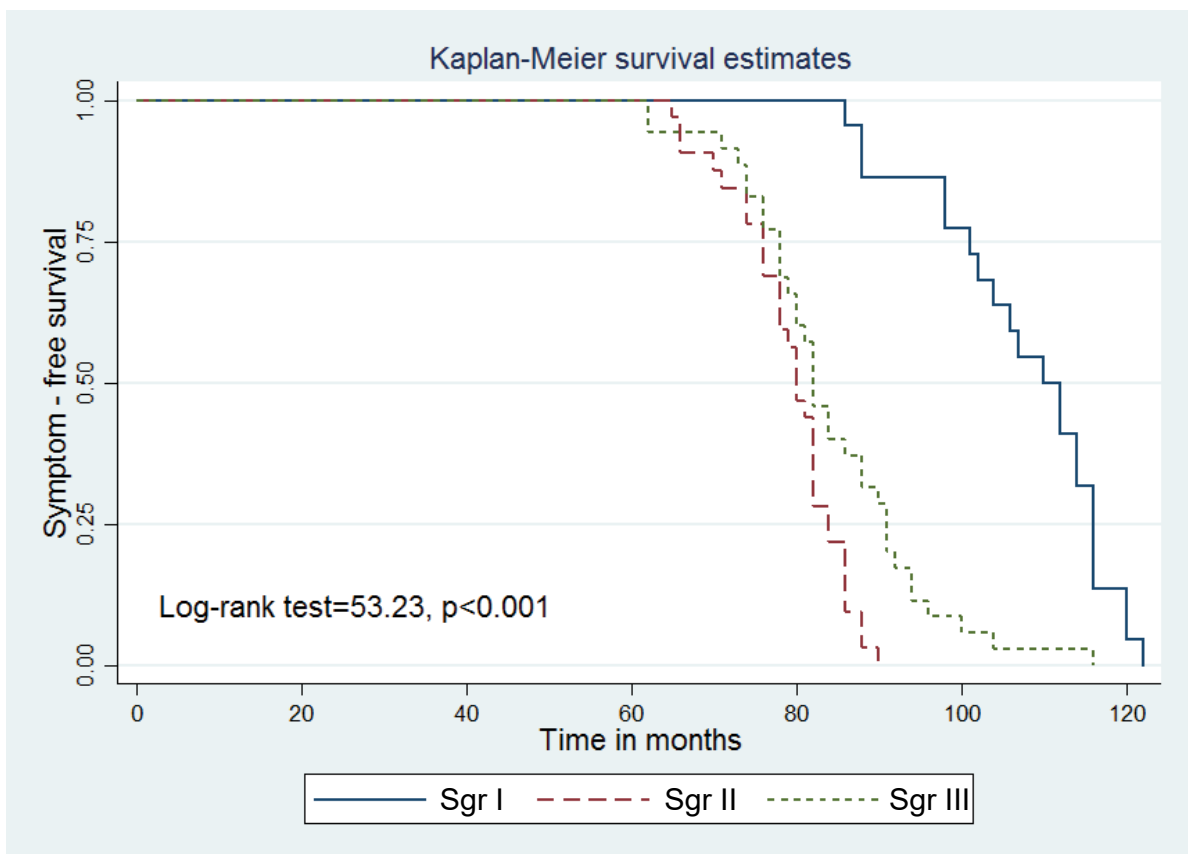

Figure 1: Symptom free disease progression in HIV-1 positive voluntary donors within the three subgroups: co-infected with HPgV (Sgr I), with TTV (Sgr II), and without co-infection with HPgV or TTV (Sgr III) respectively.

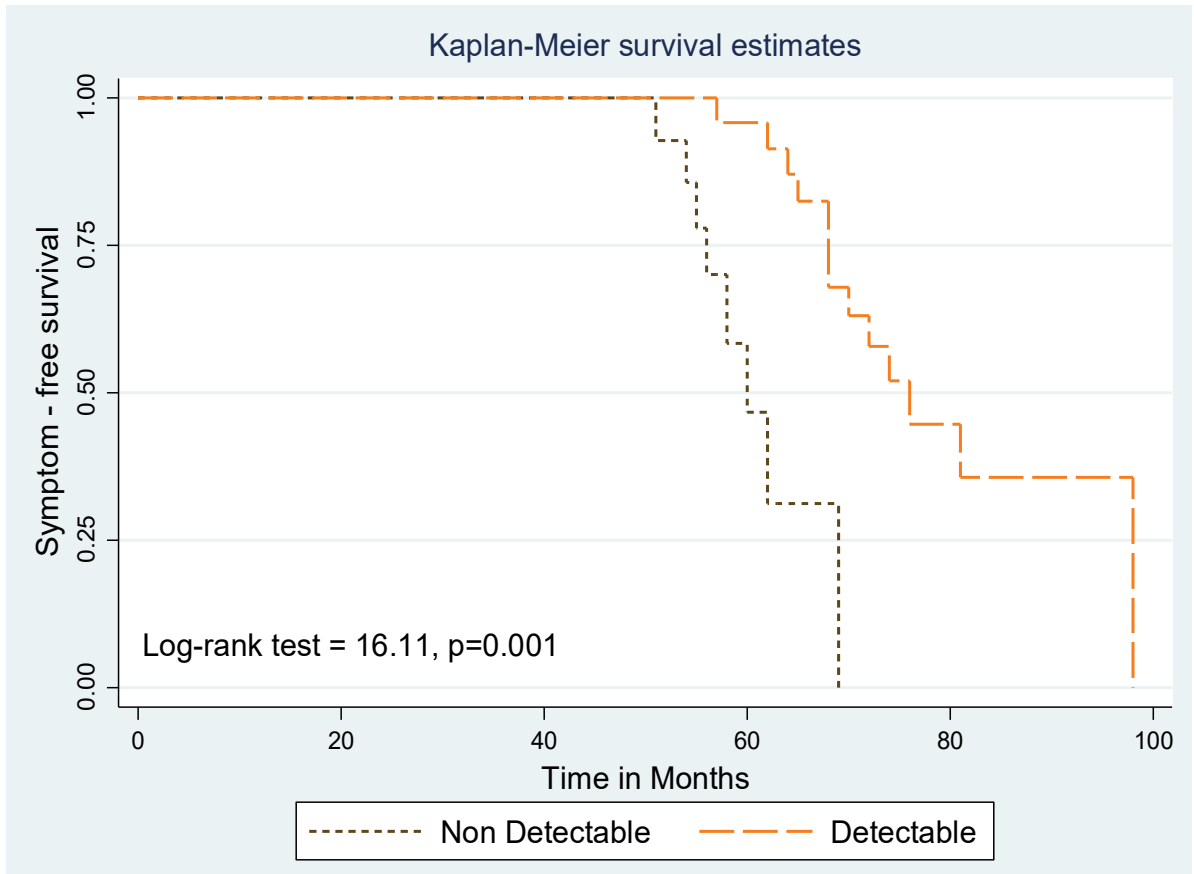

Figure 2: Symptom free disease progression in HIV-1 positive replacement donors co-infected with HPgV in relation to HPgV viremia at $3^{\text {rd }}$ year post-enrollment. 
our earlier studies, we observed that many paid donors ingested an arbitrary amount of iron tablets to maintain a qualifying hemoglobin level, allowing them to donate under false identities more frequently than was allowed per the national guideline [11]. Despite frequent donation, these donors showed biochemical evidence of iron overload because most consumed more iron than was lost through blood donation and many had concomitant history of frequent alcohol consumption that is known to facilitate intestinal iron absorption [11]. Despite non-disclosure by many donors, positive history of oral iron intake was confined to only the replacement category of donors in the present study. Normalization of iron parameters on follow up for replacement donors provides further indirect evidence of possible iron consumption by this category of donors because these donors likely ceased consumption of iron tablets now that they are disqualified from any further donation due to their HIV-1 status. HPgV is transmitted predominantly through parenteral route [1]. Thus higher representation of replacement donors compared to voluntary donors in HIV-1/HPgV subgroup could be a reflection of higher frequency of blood donation by donors this subgroup.

The unaltered profile of liver enzymes recorded among HIV-1/HPgV and HIV-1/TTV subgroups of donors at enrollment and at follow up suggests lack of any pathogenic effect of these two viruses on liver [28,29]. Despite comparable baseline levels of CD4+ T cell counts and HIV-1 plasma viral load in all the three subgroups at enrollment, rate of fall in CD4+ T cell count and rate of increase in HIV-1 plasma viral load were significantly lower among HIV-1/HPgV voluntary donors compared to HIV-1/TTV and HIV-1-only voluntary donors, suggesting a beneficial effect of HPgV co-infection on the rate of HIV-1 related disease progression. However, the beneficial effect was not apparent when the assessment was made in the HIV-1/HPgV subgroup on the whole due to masking of these changes by a higher rate of fall in CD4+ T cell count and increased plasma viral load in replacement donors.

Admittedly, the duration of HIV-1 infection could not be precisely calculated in the present study due to lack of reliable information regarding the time of unsafe heterosexual exposure. However, it can be reasoned that the enrolled donors in the present study were all in their early stage of HIV-1 infection because of our requirements of asymptomatic clinical status and unimpaired CD4+ T cell counts (> 500 cells/cumm) for their inclusion in the study. Moreover, in India, it is not uncommon for individuals to donate blood shortly following high-risk exposure for the sake of finding out their HIV status [30].

Serum levels of TNF alpha and its two receptors, TNFRI and TNFRII, have been considered to correlate with levels of immune activation in HIV-1 infection [31,32]. NF-kB is a family of transcription factors present in many mammalian cells including those involved in immune response [33]. On activation following infections, the main $65 \mathrm{kDa}$ transactivation domain of NF-kB, i.e. NF-kB p65 or Rel A migrates (translocates) from cytoplasm to nucleus where it plays a pivotal role in triggering the pro-inflammatory cytokine response. Several studies have pointed out that iron overload leads to activation of NF-kB and subsequent increases in HIV-1 replication by virtue of its binding to the Long Term Repeat (LTR) region of the HIV-1 genome [34,35]. Thus, it may be postulated that heightened immune activation in HIV-1/HPgV replacement donors was due to the increased level of iron detected among them, resulting in a more rapid loss of CD4 cells, higher plasma viral load and more rapid disease progression than the voluntary donors in the same category. Additionally, it has been suggested that ingestion of oral iron may result in subclinical damage to intestinal mucosa resulting in invasion of microbes responsible for immune activation leading to increased HIV-1 replication [36]. Significantly lower degree of immune activation (as assessed by serum levels of TNF- $\alpha$, TNFRI, TNFRII, NF-kB level in PBMC nuclear extracts, rate of fall in CD4+ T cell count, and decreased plasma viral load) in HIV-1/HPgV voluntary donors compared to voluntary donors lacking HPgV co-infection supports previous reports of HPgV co-infection suppressing HIV-1 disease progression [5,6]. However, the beneficial effect of HPgV on HIV-1 disease progression could easily be masked or overlooked as a result of including replacement donors in the analysis, which demonstrates opposite virological and immunological parameters due to their association with iron overload.

Higher rate of decline in CD4+ T cell count demonstrated by the subset of replacement donors showing loss of HPgV viremia compared to those with persistent $\mathrm{HPgV}$ viremia at a similar assessment point suggests a relationship between the two events. A larger cohort study evaluating disease progression in HIV-1 infected subjects co-infected with HPgV (previously termed GBV-C/HGV) concluded that loss of CD4+ T cell as the cause rather than loss of HPgV viremia [37]. Thus it is possible that high rate of decline in CD4+ $T$ cell count in HIV-1/HPgV replacement donors might have resulted loss of HPgV and eventual loss of beneficial effect induced by HPgV on HIV-1 disease progression. Admittedly however, repeat assessment of CD4 cell count at the point of disappearance of HPgV viremia would have provided more direct evidence to support this conclusion, although rapid loss of CD4 cell count was observed during the first year of post-enrollment. Nevertheless, the present study supports a beneficial role of $\mathrm{HPgV}$ co-infection in HIV-1 related disease progression that can be abrogated by subclinical iron overload.

\section{Conclusion}

The present study supports the view that HPgV co-infection plays a beneficiary role in HIV-1 disease 
progression and such beneficial effect is dependent on adequate availability of peripheral CD4+ $T$ lymphocytes to support HPgV viremia persistence. However, this beneficial influence may be masked due to effect of other factors that need to be carefully evaluated, such as iron overload, even at subclinical level as observed in the present study. The study further highlights the need to phase out India's dependency on replacement category of donors with questionable identity and recommends generating an adequate pool of voluntary donors for safe blood transfusion services in the country.

\section{Limitations of the Study}

(i) The beneficial effect of HPgV on HIV-1 disease progression was based on symptom free interval till the development of ARI (considered as the end point of the study) so as to avoid confounding effect of ART considering that India's HIV-1 positive subjects have a high dropout rate and inconsistent adherence to ART. Therefore, it was not possible to comment on whether the observed beneficial effect of HPgV can be extrapolated to also occur during the course of ART.

(ii) In the present study there were multiple laboratory variables. Admittedly, considering the modest sample size, it has not been possible for us to undertake a multivariate analysis. Therefore, observations in the present study have been based on univariate analysis.

\section{Data Availability Statement}

The numerical data used to support the findings of the study are included within the article. Additional information may be made available from corresponding author in compliance with ethical considerations.

\section{Conflict of Interests}

The authors declare that there is no conflict of interests regarding the publication of this paper.

\section{Funding}

This study was carried out with institutional support.

\section{Acknowledgement}

Authors are grateful to Dr. Onkar Swamy, Ex Ph.D. Scholar, University of Delhi for his help in statistical analysis of the data. The authors also thank Dr. Mallory Smith, Ph.D. for her diligent proofreading during manuscript preparation.

\section{References}

1. Abe K (2001) GB Virus-C/ Hepatitis G virus (Review). Jpn J Infect Dis 54: 55-63.

2. Oliviera LA, Martins RMB, Carneiro MAS, Teles SA, Silva SA, et al. (2002) Prevalence and genotypes of GB virus $\mathrm{C} /$ Hepatitis $\mathrm{G}$ virus among blood donors in Central Brazil. Mem Inst Oswaldo Cruz 97: 953-957.

3. Charlton M, Adjei P, Poterucha J, Zein M, Moore B, et al (1998) TT virus infection in North American blood donors, patients with fulminant hepatic failure, and cryptogenic cir- rhosis. Hepatology 28: 839-842.

4. Desai SM, Muerhoff AS, Leary TP, Erker JC, Simons JN, et al. (1999) Prevalence of TT virus infection in US blood donors and populations at risk for acquiring parenterally transmitted viruses. J Infect Dis. 179: 1242-1244.

5. Heringlake S, Ockenga J, Tillmann HL, Trautwein C, Meissner D, et al. (1998) $G B$ virus $C /$ hepatitis $G$ virus infection: A favorable prognostic factor in human immunodeficiency virus-infected patients? J Infect Dis 177: 1723-1726.

6. Lefrère $\mathrm{JJ}$, Roudot-Thoraval F, Morand-Joubart L, Petit JC, Lerable J, et al (1999) Carriage of GB virus C/hepatitis G virus RNA is associated with a slower immunologic, virology, and clinical progression of human immunodeficiency virus disease in coinfected persons. J Infect Dis 179: 783-789.

7. Sabin CA, Devereux H, Kinson Z, Griffioen A, Brown D, et al. (1998) Effect of coinfection with hepatitis $G$ virus on HIV disease progressive in hemophilic men. J Acquir Immune Defic Syndr Hum Retrovirol 19: 546-548.

8. Birk M, Lindbäck S, Lidman C (2002) No influence of GB virus $C$ replication on the prognosis in a cohort of HIV-1-infected patient. AIDS 16: 2482-2485

9. Desai MM, Pal RB, Banker DD (2004) GB virus C/hepatitis $G$ virus infection in Indian blood donors and high risk groups. Transfus Apher Sci 30: 111-117.

10. Arankalle VA, Gandhe SS, Deshmukh TM, Chadha MS, Walimbe AM (2000) Prevalence and phylogenetic analysis of TT virus DNA in Western India. Clin Diagn Lab Immunol 7: $845-849$

11. Chattopadhya D, Baveja $U$ (2018) High incidence of pulmonary tuberculosis in ART naive remunerated blood donors with human immunodeficiency virus Type-1 infection: Possible role of iron overload. J Biosci Med 6: 62-82.

12. Chattopadhya D (2018) Possible involvement of nuclear factor kappa $b$ in rapid disease progression in ART naïve HIV-1 infected remunerated blood donors with history of oral iron intake. J Biosci Med 6: 66-76.

13. National AIDS Control Organization (2007) Ministry of Health and Family Welfare, Government of India publication 'Voluntary Blood Donation Program: An operational guideline' New Delhi.

14. Zingue $D$, Hien $H$, Drabo $A$, Nouctara $M$, Kabore $A$, et al. (2014) Comparative evaluation between the new BD FACS count system and standard BD FACS count system by enumeration of absolute CD4 T lymphocytes in adults: preliminary results. J Clin Diagn Res 2: 103.

15. National AIDS Control Organization (2018) Ministry of Health and Family Welfare, Government of India, National Technical Guidelines on Anti-retroviral treatment.

16. World Health Organization (2007) Case definitions of HIV for surveillance and revised clinical staging and immunological classification of HIV related disease in adults and children, Geneva.

17. Verghese A, Singh SN, Chattopadhya D (2017) Trace element levels, cytokine profile and immune activation status in plasma among repeat blood donors with asymptomatic HIV-1, HBV and HCV infection. J Biosci Med 5: 75-94.

18. Mayo Clinic USA (2015) Information Sheet: Liver function tests; Tests and Procedures.

19. Verghese A, Arora JS, Sharma U, Rai A, Chattopadhya D (2018) Divergent pro-inflammatory cytokine response Induced by GB Virus C/ Hepatitis G virus (GBV- C/HGV) and Torque Teno Virus (TTV) co-infections in Hepatitis $C$ virus 
(HCV) infected thalassemia patient. J Mol Biol Res 8: 137152.

20. Jackson JB, Piwowar-Manning E, Johnson-Lewis L, Bassett R, Demeter LM, et al. (2004) Comparison of Versions 1.0 AND 1.5 of the Ultrasensitive AMPLICOR HIV-1 MONITOR Test for subjects with low viral load. J Clin Microbiol 42: $2774-2776$.

21. Zheng S, Brown MC, Taffet SM (1993) Lipopolysaccharide stimulates both nuclear localization of the Nuclear Factor kappa B 50-kDa subunit and loss of the 105-kDa precursor in RAW264 macrophage-like cells. J Biol Chem 268: 17233-17239.

22. Yu XP, Bellido T, Manolagas SC (1995) Down-regulation of NF- kappa B protein levels in activated human lymphocytes by 1,25 -dihydroxyvitamin D3. Proc Natl Acad Sci USA 92: 10990-10994.

23. Kasper DL, Fauci AS, Hauser SL, Longo DL, Jameson JL, et al. (2015) Harrison's 'Principles of Internal Medicine' Tata McGraw Hills, New York, USA.

24. Aggarwal V, Prakash C, Yadav S, Chattopadhya D (1997) Prevalence of transfusion associated infections in multitransfused children in relation to mandatory screening of HIV in donated blood. Southeast Asian J Trop Med Public Health 28: 699-706.

25. Chattopadhya D, Aggarwal R, Prakash C, Sen S, Kumari $S$ (1997) Sexually Transmitted Disease (STD) markers in multi-transfused children in relation to Human Immunodeficiency Virus Type-1 (HIV-1) infection. Impact of STD markers in blood donors. J Trop Ped 43: 178-181.

26. Jain R, Gupta G (2012) Family/ friend donors are not true voluntary donors. Asian J Transfus Sci 6: 29-31.

27. Singh PJ, Bhat $H(2017)$ Is there a need to phase out replacement blood donors by voluntary blood donors in hospital based blood transfusion services? Iraqi J Hematol 6: 43-48.
28. Alter HJ (1996) The cloning and clinical implications of HGV and HGBV-C. N Eng J Med 334: 1536-1537.

29. Jeon MJ, Shin JH, Suh SP, Lim YC, Ryang DW (2003) TT virus and hepatitis $G$ virus infections in Korean blood donors and patients with chronic liver disease. World J Gastroenterol 9: 741-744.

30. World Health Organization (2014) Blood donor counseling: Implementation guidelines, World Health Organization publication in collaboration with CDC and International Federation of Red Cross and Red Crescent Societies.

31. Appay V, Sauce D (2008) Immune activation and inflammation in HIV-1 infection: Causes and consequences. J Pathol 214: $231-241$.

32. Younas M, Psomas C, Reynes J, Corbeau P (2016) Immune activation in the course of HIV-1 infection: Causes, phenotypes and persistence under therapy. HIV Med 17: 89-105.

33. Hiskott J, Kwon H, Genin P (2001) Hostile takeovers: Viral appropriation of the NF-kB pathway. J Clin Invest 107: 143151.

34. Sappey C, Boelaert JR, Legrand-Poels S, Forceille C, Favier A, et al. (1995) Iron chelation decreases NF-kappa B and HIV type 1 activation due to oxidative stress. AIDS Res Human Retro 11: 1049-1061.

35. West MJ, Lowe AD, Karn J (2001) Activation of Human Immunodeficiency Virus Transcription in T Cells revisited: NF-kappaB p65 stimulates transcriptional elongation. J Virol 75: 8524-8537.

36. De Sousa M (1989) Immune cell functions in iron overload. Clin Exp Immunol 75: 1-6.

37. Van Der Bij AK, Kloosterboer N, Prins M, Boeser-Nunnink B, Geskus RB, et al. (2005) GB Virus C co-infection and HIV-1 disease progression: The Amsterdam Cohort Study. $\mathrm{J}$ Infect Dis 191: 678-685. 


\section{Supplementary materials}

\section{Supplementary material 1 (Materials and methods)}

\section{Molecular detection of HPgV, TTV, HBV and HCV}

(i) Extraction of DNA for HBV and TTV from serum: DNA for HBV and TTV was extracted from serum samples by Proteinase $\mathrm{K}$ extraction method using manufacturer's protocol (DNA Sure Blood Mini Kit, Nucleopore, Genetix Biotech Asia Pvt. Ltd.). Briefly, $200 \mu$ of serum was mixed with the same volume of Proteinase $\mathrm{K}$ and lysis buffer after 10 minutes incubation period at room temperature, the mixture was centrifuged, washed twice with wash buffer and finally eluted in $100 \mu \mathrm{l}$ of elution buffer provided with the kit. Quality of the genomic DNA was checked by $1 \%$ agarose gel electrophoresis run on $0.5 \mathrm{X}$ Tris-acetate EDTA (TAE) buffer. The bands were visualized in UV-transilluminator.

(ii) Extraction of RNA for HPgV and HCV from serum: Viral RNA for HCV and HPgV was extracted from serum sample using the QIAmp Viral RNA Kit (Qiagen, Hildon, Germany) according to the manufacturer's protocol. Briefly, $140 \mu \mathrm{l}$ of serum was mixed with viral lysis buffer ( $200 \mathrm{mM} \mathrm{NaOH}, 1 \%$ SDS) and was further treated with proteinase $\mathrm{K}$ and carrier RNA (provided with the kit). After 10 minutes of incubation at room temperature the RNA was precipitated with ethanol, washed twice with washing buffer and finally eluted in $60 \mu \mathrm{l}$ of elution buffer $(1.25 \mathrm{M} \mathrm{NaCl}, 50 \mathrm{mM}$ Tris- $\mathrm{HCl})$ provided with the kit. The quality of RNA was checked by the same procedure mentioned above for HBV and TTV.

(iii) PCR Amplifications: The extracted DNA was amplified by PCR for pre-core/core and partial pol genes of HBV (amplicon size $1078 \mathrm{bp}$ ) and conserved 5' end region of TTV (amplicon size $199 \mathrm{bp}$ ). The extracted RNA was amplified by nested RT-PCR for conserved 5' UTR gene of HCV (amplicon size 250 bp) and 5' NTR gene of HPgV (amplicon size 204 bp). The outer PCRs (RT-PCR) for HPgV and HCV were carried out using GeneAmp Gold RNA PCR Core Kit while all the DNA PCRs of TTV, HBV and inner PCRs of HCV and HPgV were carried out using Go Taq Green Master Mix (Promega, Madison, USA) kit according to manufacturer's instructions. Concentration of primers used in all the rounds of PCR was 10 pmol. The polymerase chain reaction was performed in GeneAmp PCR system 9700 (Applied Biosystems) in $200 \mu$ l Micro-Amp reaction tubes. The amplified product was analyzed on $2 \%$ agarose gel under UV light after staining with ethidium bromide (PCREB). In every PCR run two positive and two negative samples were included and run in duplicate until congruent results, only were accepted. The primer sequences for HBV was F-GGAGTTGGGGGAGGAGATTA, R-AGGCGCTACGTGTTGTTTCT and for TTV F-GCTACGTCACTAACCACGTG, R-CTBCGGTGTGTAAACTCACC respectively. For HCV outer primer sequence as F-CTGTGAGGAACTACTGTCTT, R-ATACTCGAGGTGCACGGTCTACGAGACCT; inner PCR sequences as F-TTCACGCAGAAAGCGTCTAG, R-ACTCTCGAGCACCCTATCAGGCAGT respectively. The HPgV outer PCR sequence as F-AAGCCCCAGAAACCGACGCC, R- TGAAGGGCGACGTGGACCGT and inner sequences as F-CGGCCAAAAGGTGGTGGATG， R-GTAACGGGCTCGGTTTAACG respectively.

PCR cycling conditions were as follows. Briefly, for HBV initial denaturation was carried out at $95^{\circ} \mathrm{C}$ for $5 \mathrm{~min}$. followed by amplification comprising of 37 cycles of alternate $94{ }^{\circ} \mathrm{C}$ for $1 \mathrm{~min} ; 55^{\circ} \mathrm{C}$ for $1 \mathrm{~min} ; 72{ }^{\circ} \mathrm{C}$ for $2 \mathrm{~min}$. and final extension at $72{ }^{\circ} \mathrm{C}$ for $10 \mathrm{~min}$. For TTV, initial denaturation at $95{ }^{\circ} \mathrm{C}$ for 5 min. followed by amplification comprising of 55 cycles of alternate $94^{\circ} \mathrm{C}$ for $15 \mathrm{sec} ; 60^{\circ} \mathrm{C}$ for $15 \mathrm{sec} ; 72^{\circ} \mathrm{C}$ for $20 \mathrm{sec}$. and final extension at $72{ }^{\circ} \mathrm{C}$ for $7 \mathrm{~min}$. Outer PCR for HCV, cDNA synthesis at $45^{\circ} \mathrm{C}$ for $45 \mathrm{~min}$ and initial denaturation at $95^{\circ} \mathrm{C}$ for $10 \mathrm{~min}$. followed by amplification comprising of 35 cycles of alternate $95^{\circ} \mathrm{C}$ for $30 \mathrm{sec} ; 48^{\circ} \mathrm{C}$ for $30 \mathrm{sec} ; 72{ }^{\circ} \mathrm{C}$ for $30 \mathrm{sec}$; and a final extension at $72{ }^{\circ} \mathrm{C}$ for $7 \mathrm{~min}$., whereas for inner PCR initial denaturation at $95^{\circ} \mathrm{C}$ for 5 min followed by amplification comprising of 35 cycles of alternate $94^{\circ} \mathrm{C}$ for $30 \mathrm{sec}$; $50{ }^{\circ} \mathrm{C}$ for $30 \mathrm{sec} ; 72{ }^{\circ} \mathrm{C}$ for $30 \mathrm{sec}$; and a final extension of 72 ${ }^{\circ} \mathrm{C}$ for $7 \mathrm{~min}$. For HPgV, cDNA synthesis was carried out at 45 ${ }^{\circ} \mathrm{C}$ for $45 \mathrm{~min}$. initial denaturation at $95^{\circ} \mathrm{C}$ for $10 \mathrm{~min}$ followed by amplification comprising of 35 cycles of alternate $95^{\circ} \mathrm{C}$ for $30 \mathrm{sec} ; 65^{\circ} \mathrm{C}$ for $30 \mathrm{sec} ; 72^{\circ} \mathrm{C}$ for $30 \mathrm{sec}$. and final extension at $72{ }^{\circ} \mathrm{C}$ for $7 \mathrm{~min}$. For Inner PCR initial denaturation was carried out at $95^{\circ} \mathrm{C}$ for $5 \mathrm{~min}$. followed by amplification consisting of 30 cycles of $60^{\circ} \mathrm{C}$ for $15 \mathrm{sec} ; 56^{\circ} \mathrm{C}$ for $20 \mathrm{sec} ; 72^{\circ} \mathrm{C}$ for $25 \mathrm{sec}$. and final extension at $72{ }^{\circ} \mathrm{C}$ for $7 \mathrm{~min}$.

\section{Supplementary material 2 (Materials and methods)}

\section{Protocol for quantitation of NF-kB p65 level in nuclei of LPS stimulated PBMCs}

The protocol involved four steps: (i) Isolation of PBMCs (ii) Treatment of PBMCs with mitogen LPS to induce translocation of NF-kB p65 from cytoplasm into the nucleus (iii) Extraction of nuclear proteins from LPS stimulated PBMCs and (iv) Estimation of NF-kB p65 in nuclear protein extracts of LPS stimulated PBMCs.

(i) Isolation of PBMCs: Mononuclear cells were isolated from blood collected in EDTA by layering on Ficoll hypaque (specific gravity 1.077 ) followed by density gradient centrifugation at $400 \mathrm{~g}$ for 30 minutes at $22^{\circ} \mathrm{C}$. Interphase cells were recovered, washed 3 times in Hanks balanced salt solution (HBSS) and suspended in Iscove's modified Dulbecco's medium (IMDM, Sigma Chemicals, USA) with $25 \%$ heat inactivated human serum supplemented with Gentamycin Sulfate $(40 \mu \mathrm{g} /$ $\mathrm{ml}$ ) and Amphotericin B $(0.25 \mu \mathrm{g} / \mathrm{ml})$. The endotoxin content of the medium, as tested by Limulus lysate assay, was negligible $(<0.1 \mathrm{ng} / \mathrm{ml})$. The PBMC suspension was found to contain $>95 \%$ of viable cells by trypan blue exclusion method and $>$ 97\% pure PBMCs by flow cytometric analysis using monoclonal anti-CD3, anti-CD19 and anti-CD14 antibodies. The PBMC suspension was adjusted to $1 \times 10^{6}$ cells $/ \mathrm{ml}$.

(ii) Treatment of PBMCs with LPS: Approximately $1 \times 10^{7}$ cells in $1 \mathrm{ml}$ tube was subjected to treatment with LPS (derived from Escherichia coli, serotype 0111:B4, Sigma chemicals, USA), $10 \mathrm{ng} / \mathrm{ml}$, to facilitate translocation of NF-kB p65 from cytoplasm into nucleus and incubated overnight at $37^{\circ} \mathrm{C}$ in a humidified $5 \% \mathrm{CO}_{2}$ chamber.

(iii) Extraction of nuclear proteins from LPS stimulated PBMC nuclei: This procedure was carried out in presence of protease inhibitor cocktail to prevent loss of extracted protein.

\section{(a) Reagents used}

The reagents for extracting proteins (Nonidet P-40, 
HEPES, DTT (DL- Dithiothreitol), $\mathrm{MgCl}_{2}, \mathrm{KCL}$, Tris-HCl, Na-EDTA and Glycerol) were all procured from local supplier (Hi-Media Laboratories, India). The reagents for preparation of protease inhibitor cocktail as per concentrations mentioned were all procured from a different source (Sigma chemicals, USA) (Phenyl-methyl-sulfonyl fluoride (PMSF, Cat No P7626) 0.5 $\mathrm{mM}$, Leupeptine (Cat No L8511) $1 \mathrm{mg} / \mathrm{ml}$, Pepstatin (Cat No P 4625) $0.5 \mathrm{mg} / \mathrm{ml}$, Aprotinin (Cat No A1153) $1 \mathrm{mg} / \mathrm{ml}$, EGTA (Cat No E8145) $1 \mathrm{mM}$, Sodium orthovanadate $\left(\mathrm{Na}_{3} \mathrm{VO}_{4}\right.$, Cat No S6508) $1 \mathrm{mM}$ ). PMSF was prepared fresh each time before use.

\section{PBMCs}

(b) Extraction of nuclear protein from LPS stimulated

LPS treated PBMC suspension was centrifuged at $750 \mathrm{~g}$ at $4{ }^{\circ} \mathrm{C}$. The pellet was washed twice with cold HEPES buffer followed by suspension in 20-40 $\mu$ lice cold hypotonic HEPES buffer composed of HEPES (10 mM, pH 7.8), $\mathrm{MgCl}_{2}(1.5 \mathrm{mM})$, KCL (10 mM), DTT $(0.5 \mathrm{mM})$ containing $0.1 \%$ Nonidet P-40. The suspension was kept on ice for 10 minutes followed by centrifugation at $10,000 \mathrm{~g}$ for 10 minutes. The pellet representing nuclear fraction was re-suspended in 35-40- $\mu$ icecold high salt buffers (20 mM HEPES pH 7.9, $420 \mathrm{mM} \mathrm{NaCl}$, $1.5 \mathrm{mM} \mathrm{MgCl}, 0.2 \mathrm{mM}$ EDTA and 25\% Glycerol) containing $10 \mu$ of protease inhibitor cocktail, followed by incubation at $4{ }^{\circ} \mathrm{C}$ for 15 minutes with intermittent shaking. The suspension containing lysed nuclei was vortexed and centrifuged at $10,000 \mathrm{~g}$ at $4{ }^{\circ} \mathrm{C}$ for 10 minutes for settling the nuclear debris. The supernatant representing the nuclear extract was collected and stored at $-80^{\circ} \mathrm{C}$ with addition of $75-100 \mu$ of HEPES buffer ( $\mathrm{pH}$ 7.9). The protein concentration of the extract was determined by Bradford's method in 96 well micro plate using Coomassie dye reagent with bovine serum albumin as calibration standards. The concentration of protein in nuclear extract suspension was adjusted to $100 \mu \mathrm{g} / \mathrm{ml}$.

\section{(iii) Estimation of NF-kB p65 in nuclear fraction}

This procedure was carried out by utilizing triplicate wells per sample in a commercial micro-well ELISA kit as per manufacturer's protocol (Cusabio, Wuhan, China; sensitivity 0.047 $\mathrm{ng} / \mathrm{ml}$, intra-assay and inter-assay coefficient of variation < $10 \%)$. Concentration of NF-kB p65 in the nuclear extract was expressed as nanogram (ng) of NF-kB p65 per microgram ( $\mu \mathrm{g})$ of nuclear protein extract after taking the average of three wells.

\section{Supplementary materials 3 (Results)}

\section{Serum levels of liver enzymes and iron parameters in serum at enrollment and at follow up}

(i) Liver enzymes levels (mean \pm SD) in subgroups I, li and III

(a) At enrollment:

$\operatorname{ALT}(U / L): 36.2 \pm 11.2,34.1 \pm 10.5$ and $33.8 \pm 11.5$

$\operatorname{AST}(U / L): 29.7 \pm 11.2,28.8 \pm 7.9$ and $27.9 \pm 8.8$

$\operatorname{ALP}(\mathrm{U} / \mathrm{L}): 86.1 \pm 20.1,87.6 \pm 19$ and $84.1 \pm 21.2$

Serum bilirubin $(\mathrm{mg} / \mathrm{dL}): 0.66 \pm 0.08,0.54 \pm 0.07$ and 0.53 $\pm 0.06$

(b) At follow up point:

No statistically significant change could be recorded compared to their enrollment levels (mean \pm SD) in subgroups I, II and III

$\operatorname{ALT}(\mathrm{U} / \mathrm{L}): 35.3 \pm 8.4,32.8 \pm 11.2$ and $33.2 \pm 10.7$

$\operatorname{AST}(U / L): 26.7 \pm 8.6,26.0 \pm 9.2$ and $26.2 \pm 9.4$

ALP (U/L): $82.3 \pm 19.9,81.2 \pm 20.0$ and $82.2 \pm 21.3$

Serum bilirubin $(\mathrm{mg} / \mathrm{dL}): 0.62 \pm 0.03,0.51 \pm 0.05$ and 0.52 $\pm 0.05$

Non-donor controls

$\operatorname{ALT}(\mathrm{U} / \mathrm{L}): 31.9 \pm 8.9, \mathrm{AST}(\mathrm{U} / \mathrm{L}): 25.8 \pm 7.2, \mathrm{ALP}(\mathrm{U} / \mathrm{L}): 81.1$ \pm 17.4 , Serum bilirubin $(\mathrm{mg} / \mathrm{dL}): 0.64 \pm 0.03$.

\section{(ii) Serum iron parameters:}

Elevated levels of various iron parameters in replacement donors came down to normal levels in all the three subgroups as assessed at follow up point with values of serum iron ( $\mu \mathrm{mol} / \mathrm{L})$, transferrin saturation (\%) and ferritin $(\mu \mathrm{g} / \mathrm{L})$ as $16 \pm 3.6,34.5 \pm 4.9$ and $66.8 \pm 21.6$ respectively in subgroup I, $19.1 \pm 5.2,33.6 \pm 3.3$ and $80.8 \pm 17.9$ respectively in subgroup II, and $18.1 \pm 4.9,35.3 \pm 5$ and $80 \pm 21.2$ respectively in subgroup III. 